\title{
RELIGIOSIDAD Y RITUALES HISPANOS EN AMÉRICA ANTE LOS DESASTRES (SIGLOS XVI-XVII): LAS PROCESIONES*
}

\author{
María Eugenia Petit-Breuilh SepúlVeda \\ Universidad de Sevilla \\ mepetit@us.es
}

\section{Resumen}

En esta investigación se analiza el efecto que tuvieron los desastres en los rituales y ceremonias de los hispanos en América durante los siglos XVI y XVII con el objetivo de buscar modelos de comportamiento. Este estudio se abordó en el largo período para poder percibir cambios y permanencias en las conductas de la población utilizando las descripciones de estas prácticas documentadas especialmente por sus protagonistas, por este motivo se revisaron fuentes de varios archivos y bibliotecas especializadas realizando un análisis crítico de los datos obtenidos. Sin duda, las reacciones religiosas se manifestaron tras los desastres como una forma de responder a la mentalidad providencialista de la época y las procesiones sirvieron como columna vertebradora de otros rituales que se hacían en el mismo sentido: aplacar la «ira de Dios» por los pecados cometidos.

Palabras clave: religiosidad, desastres, terremotos, erupciones volcánicas, procesiones, siglos XVI-XVII.

* La realización de este estudio ha dispuesto de una ayuda económica del Plan Andaluz de Investigación de la Junta de Andalucía concedida al Grupo de Investigación «Mentalidad, sociedad y medioambiente en Andalucía e Iberoamérica en la Edad Moderna» (HUM-785). 


\begin{abstract}
Religiosity and Hispanic rituals in America to face of disasters (XVI-XVII centuries): The processions

This research analyzes the effect of disasters on the rituals and ceremonies of Hispanics in America during the XVI-XVII centuries in order to search for patterns of behavior. This study was approached in the long period in order to be able to perceive changes and permanences in the behaviors of the population using the descriptions of these practices especially documented by its protagonists, for this reason sources of several archives and specialized libraries were reviewed conducting a critical analysis of the data obtained. Undoubtedly, religious reactions were manifested after disasters as a way of responding to the providentialist mentality of the time and processions served as a backbone of other rituals that were done in the same direction: placate the «wrath of God» by the committed sins.
\end{abstract}

Keywords: religiosity, disasters, earthquakes, volcanic eruptions, processions, XVIXVII centuries.

\title{
Introducción
}

Dentro del conjunto de comportamientos que han generado los desastres en la población hispanoamericana relacionados con terremotos, erupciones volcánicas, sequías y procesos asociados, las relacionadas con la religiosidad ${ }^{1}$ se encuentran entre las más características; no obstante, habitualmente las descripciones y los estudios se han dedicado mayoritariamente a reseñar la reacción de los distintos colectivos sociales ante terremotos concretos. Por este motivo, en esta investigación se analiza la religiosidad de los hispanos ante las catástrofes naturales en general, identificando aquellos procedimientos que permitan establecer modelos de actuación en este tipo de situaciones, poniendo un especial interés en algunos rituales y ceremonias

1. En torno a la polémica historiográfica que ha existido sobre los conceptos de religiosidad y religiosidad popular puede verse, entre otras, las siguientes publicaciones: SÁNCHEZ LORA, José Luis, «Religiosidad popular: un concepto equívoco» en SERRANO MARTíN, 1994: 65-79. EGIDO, 1990: 767-792. AGUILAR PIÑAL, Francisco., «Predicación y mentalidad popular en la Andalucía del siglo XVIII» en ÁlVAREZ SANTALÓ, 1989: 57-71. CORTÉS PEÑA, (1995): 1027-1042. EGIDO, Teófanes, «Religiosidad popular y Cortes tradicionales de Castilla» en Álvarez SANTALÓ, 1989, tomo II: 96-110. 
que fueron evolucionando desde el siglo XVI hasta fines del siglo XVIII como las procesiones.

En este contexto, el análisis de la religiosidad de los hispanos ante procesos naturales que superaron la capacidad de respuesta de la población nos obliga a rememorar múltiples acontecimientos que rompieron la normalidad y la cotidianeidad de hombres y mujeres que en pocos minutos u horas vieron derrumbarse todos sus esfuerzos y sus anhelos²; sabemos que ocurrieron terremotos que arruinaron las construcciones de pueblos y ciudades, acompañados de tsunamis que barrieron las costas del Pacífico arrasando todo lo que encontraban a su paso y erupciones volcánicas que oscurecieron el día de ciudades como Quito, Riobamba y Arequipa, trayendo la desolación y la desesperanza a sus habitantes y la ruina de sus campos ${ }^{3}$. En ocasiones, estos procesos naturales no llegaron solos, puesto que dieron paso a catástrofes de gran magnitud como las ocurridas en 1535 (Quito), 1541 (Guatemala), 1575 (Chile), 1582 (Perú), 1595 (Colombia), 1600 (Perú), 1647 (Chile), 1650 (Perú), 1660 (Ecuador), 1687 (Perú), 1698 (Ecuador), por citar algunas del período de estudio ${ }^{4}$.

Las fuentes utilizadas para desarrollar esta investigación fueron documentos encontrados en el Archivo General de Indias, Archivo de la Real Academia de la Historia de Madrid, Biblioteca Apostólica Vaticana, Archivum Romanum Societatis Iesu (ARSI) y Biblioteca de la Compañía de Jesús en Roma, Archivo Histórico Nacional de Chile y en el Fondo Antiguo de la Biblioteca de la Universidad de Sevilla; también fueron analizadas varias crónicas de la época investigada, reseñas e informes de misioneros, militares o viajeros que estaban en las zonas afectadas para poder extraer la información necesaria. Se recurrió también al apoyo de croquis y cartografía histórica y al análisis de la toponimia de la región para poder definir exactamente la magnitud geográfica de lo que se describió en los registros consultados.

Sobre la base de los documentos y bibliografía analizadas es posible señalar que el modelo de ritual que se adoptó para este tipo de situaciones límites fue el que se utilizaba durante la Semana Santa en su versión más solemne

2. Petit-Breuilh, 2004b: 23.

3. Petit-Breuilh, 2004a: 65-122.

4. Petit-Breuilh, 2004b: 35-63. 
y de penitencia; al menos es lo que se desprende de las Actas del Cabildo de Santiago de Chile de 18 de mayo de 1618 y 29 de mayo de 1619, cuando se convocó a las autoridades y a la comunidad para pedir lluvias debido a la sequía «para que en forma similar a las procesiones de Semana Santa, lograran de la Divinidad el agua que les faltaba ${ }^{5}$. De igual manera que el ceremonial de la conmemoración de la pasión y muerte de Cristo evolucionó hacia expresiones más barrocas a medida que transcurría el siglo XVII, las demostraciones colectivas efectuadas durante las catástrofes naturales experimentaron también esa misma tendencia. Esta situación se mantuvo incluso durante todo el siglo XVIII.

Por otra parte, en algunas regiones americanas la frecuencia de los procesos naturales que terminaban en desastre era tan alta que se fue creando una verdadera «cultura del riesgo $»^{6}$-aunque muchas veces de manera espontánea e improvisada-, situación que terminó repercutiendo en los diseños constructivos, en los materiales utilizados en las viviendas y edificios públicos y en la propia forma de vestir. De este modo, la necesidad de sobrevivir a los riesgos que el medio físico hispanoamericano le impuso a sus habitantes fue creando pequeñas iniciativas que se sumaron con el paso de los siglos y que formaron un estilo de afrontar este tipo de circunstancia. A este respecto la mayoría de los estudios sobre los hechos relacionados con los desastres ha enfocado el tema como si se tratara de una pura reacción de miedo colectivo con énfasis en la religiosidad. Ciertamente, la respuesta religiosa del grupo -quizá el rasgo más evidente en las fuentes históricas- respondía a más razones que la sola reacción ante el castigo divino o el temor a la muerte.

Sin duda, el ambiente religioso dominante en Hispanoamérica durante la época colonial impuso a los hombres de este período unos deberes y normas cristianas que a parte de ellos les resultarían tediosos o simplemente no les interesaba realizar; pero en situaciones límites, como fue el caso de algunas catástrofes naturales, se apresuraron a llevarlos a cabo. Ejemplo de ello fue el cumplimiento con la confesión, la comunión y el matrimonio, tres de los sacramentos que tuvieron más demanda por parte de los feligreses en este tipo de sucesos; esta actitud se entiende si se recuerda que los hispanos le

5. Actas del Cabildo de Santiago de Chile en Medina, tomo XXV, 1901: 256 y 336.

6. PALACIOS, 2015: 243-251. 
asignaban un origen divino a los procesos naturales, especialmente a aquellos que alcanzaban características de desastre.

En este sentido, según el análisis de los casos seleccionados para esta investigación, una vez que las personas superaban la sorpresa inicial -momento en que cada uno velaba por su seguridad individual-, se reunían en comunidad para decidir de qué manera podían resolver lo que les estaba sucediendo. A este respecto y atendiendo a que durante la época colonial la creencia generalizada apuntaba a que los desastres ocurrían debido a castigos o «advertencias de Dios» por no haber cumplido con alguna norma o no haber llevado una vida cristiana, el paso a seguir era implorar al Altísimo su perdón y misericordia, según se estipulaba en la propia Biblia; estas súplicas se organizaban de diferentes maneras teniendo cada una de las ceremonias un claro objetivo. Por otra parte, la elección del tipo de ritual dependía en cierto modo de la magnitud y persistencia del fenómeno que ellos interpretaban como la «ira de Dios»; en el caso de las catástrofes el impacto psicológico y humano que provocaban generó que se realizaran misas, procesiones rogativas de «sangre», conjuros y exorcismos ${ }^{7}$ que se dirigían a distintos elementos de la Naturaleza.

Ahora bien, si la población entendía que los rituales antes mencionados les reportaban los resultados que esperaban -o sea, lograban detener el fenómeno natural-, venía una segunda etapa de ceremonias enfocadas a la acción de gracias; estas demostraciones colectivas podían consistir en nuevas procesiones, misas cantadas, realización de misiones, canto de letanías y novenas, aunque esta vez desarrolladas en un ambiente menos dramático. Si se busca el fundamento filosófico de estas ceremonias religiosas hay que remitirse a la propia Biblia y a los mensajes que predicaron durante siglos los santos, evangelizadores y misioneros en Europa y también en América; precisamente, el discurso construido estaba basado en la idea de que si los hombres necesitaban algún favor de Dios debían invocarlo y solicitárselo expresamente. En este sentido, a principios del siglo XVII el padre Antonio de la Calancha señalaba durante su trabajo como misionero en el Perú lo siguiente: «(...) porque Dios, si quiere perdonar, quiere ser rogado, y si ha de hacer favores, quiere que se los pidan, y él da las ganas para que le rueguen. Que determina Dios en muchas cosas y predestina favores (dicen Gregorio,

7. Petit-Breuilh, 2002: 331-351. 
Agustino y Jerónimo) con tal que le rueguen primero, y en rogándole las concede al punto; y si no las ruegan no se las concede» ${ }^{8}$. Este pensamiento se mantuvo vigente durante todo el Antiguo Régimen, aunque se expresó en los distintos siglos con diferentes intensidades. De todas formas, es posible que un hispano medio que tuviera la vivencia de una catástrofe natural lo primero que haría sería encomendarse a Dios como consecuencia de lo arraigada que estaba esta creencia en la sociedad.

Se destaca que al realizar un estudio en la larga duración de diferentes catástrofes se aprecia que la actitud que expresaron los hispanoamericanos desde el siglo XVI hasta el siglo XVII tiene una directa relación con la difusión de los avances científicos y de la concepción que estos tenían de la Naturaleza. A este respecto, se observa que durante el período estudiado el enfoque providencialista marcó toda la vida de la sociedad y no se permitió oficialmente la opción de otra explicación de los hechos que ocurrían en el mundo; de esta forma, Dios y sus «razones» eran las justificaciones de las acciones bélicas, la vida cotidiana y los sucesos como sequías, erupciones volcánicas y terremotos.

\section{Procesiones rogativas, de «sangre» y otros rituales}

La procesión rogativa fue uno de los primeros rituales que se efectuaron en la América hispana cuando ocurrieron catástrofes naturales. Al menos así quedó registrado en los documentos que describen los hechos ocurridos durante la ruina de la ciudad de Santiago de los Caballeros (Guatemala) ${ }^{9}$, ubicada entre los volcanes Agua (inactivo) y Fuego (activo). El desastre se produjo entre los días 10 y 11 de septiembre de 1541 después de haber llovido copiosamente desde el 8 hasta el 10 de septiembre y con posterioridad a haberse producido un fuerte temblor a las dos horas del 11 de septiembre ${ }^{10}$. Esta conjunción de procesos creó las condiciones necesarias para que durante este día se generaran al menos dos importantes desprendimientos de una parte de la estructura del volcán Agua, ya que este material volcanoclástico y rocoso mezclado con el agua acumulada por las lluvias torrenciales de los días precedentes formaron

\footnotetext{
8. CALANCHA y TORRES, 1972: 415.

9. Esta ciudad fue fundada por el adelantado Pedro de Alvarado en 1524.

10. RODRÍGUEZ, 1543: 7.
} 
un flujo de detritos (lahar) que destruyó dos terceras partes de la ciudad. El sitio afectado entonces se conoce ahora con la denominación de Ciudad Vieja y se encuentra a escasos kilómetros al suroeste de Antigua Guatemala, localizada justamente sobre la ladera noroeste del volcán Agua ${ }^{11}$. Según los relatos y crónicas que describen el suceso hubo cientos de muertos entre la población indígena y decenas entre la hispana ${ }^{12}$. Para completar la experiencia que tuvieron que afrontar los pobladores de Santiago de los Caballeros con los procesos naturales que se sucedían en septiembre de 1541 hay que sumar la erupción del volcán Fuego, que presentaba en ese mes una actividad estromboliana más intensa que en otras ocasiones ${ }^{13}$. Los comportamientos de los pobladores españoles durante el primer momento de la catástrofe estuvieron marcados por el desconcierto y el miedo frente a lo que estaba sucediendo; por su parte, la mayoría de los indígenas, a diferencia de los colonizadores que se dedicaron a invocar a la Divinidad, reaccionaron abandonando la ciudad ${ }^{14}$. Con posterioridad, el cronista Antonio de Remesal reconstruía lo ocurrido durante las primeras horas de aquel 11 de septiembre:

Despertó la gente con tantos y tan fuertes movimientos de la tierra y dejando sus casas (...) andaban por las calles del lugar llorando a voces y a grandes gritos llamando a Dios y a los santos que los favoreciesen; con tantas veras, como quien no esperaba menos que un juicio final, y sonándole la trompeta a los oídos, vía abrirse la tierra y resucitar los muertos y el infierno abierto para tragárselo $(\ldots)^{15}$.

Tras concluir el episodio catastrófico mencionado, esperaron el amanecer para contabilizar a los heridos, los muertos y se evaluaron los daños materiales confirmándose que gran parte de los supervivientes habían perdido casi todos sus bienes. Según los relatos de la época, el obispo de Guatemala Francisco de Marroquín organizó una procesión y letanías rezadas en las que

11. Comunicación epistolar del geólogo Dr. José Viramonte, 14 de mayo de 2000. El Dr. Viramonte desarrolló durante tres años un proyecto de investigación financiado por el Fondo Argentino de Cooperación Horizontal para determinar el riesgo volcánico del volcán Agua.

12. RODRÍGUEZ, 1543: 3-5.

13. BENAVENTE, 1971: 274. Fuentes y GuZMÁN, 1969, tomo 1: 140.

14. BENAVENTE, 1971: 275.

15. REMESAL, 1964: 275. 
los participantes dieron muestras de devoción; asimismo, dirigió a los fieles un sermón para alentarlos e invitarlos a dar gracias por haber conservado la vida, aprovechando la situación originada por este desastre para inculcar en ellos un permanente temor a Dios y respeto a sus mandatos ${ }^{16}$. Esta decisión del obispo fue importante dentro del contexto de los rituales religiosos que se efectuaron desde esta fecha en adelante en la América hispana ya que sirvió de precedente y modelo. Se destaca en este caso que aunque se entendió que el origen del desastre eran los «pecados: porque tan gran tempestad no podemos saber como ni de donde vino ${ }^{17}$, sin embargo, el prelado animó a los sobrevivientes a reponerse y a «dar gracias a Dios y que quitasen los lutos de la iglesia e hízolo también, porque los naturales no pensasen que estaban desconsolados» ${ }^{18}$. Este asunto no fue menor durante la época colonial ya que el temor a los ataques indígenas en momentos de vulnerabilidad fue constante por parte de los españoles ${ }^{19}$.

Las escenas de solemnes rogativas, súplicas y oraciones se repitieron en Guatemala en 1565 debido a la erupción del Pacaya; en esta ocasión el volcán causó importantes perjuicios a la ciudad como consecuencia de los fuertes y repetidos seísmos que produjeron las explosiones ${ }^{20}$. Sin duda, los rituales religiosos se realizaban como una forma de intentar acabar con el proceso natural que les ocasionaba daños o con el fin de minimizar sus efectos; esta era la única manera que conocían los hispanos del siglo XVI para reaccionar ante unos sucesos que les parecían sobrenaturales y semejantes al propio fin del mundo descrito en el Apocalipsis. En este marco, el cabildo de Concepción de Chile, tras el terremoto del 8 de julio de 1570 que devastó a esta ciudad, se expresaba de la siguiente manera:

(...) y perseverando continuadamente hasta el día de hoy, por espacio de más de cinco meses, el dicho terremoto y temblores, nos parecía que esta ciudad y república debe ser purificada con penitencia, limosna y oraciones, que es el modo con que la divina escritura, y la santa madre iglesia, nos enseñan a aplacar y prevenir el rostro riguroso del Señor, cuya infinita clemencia se deja

\footnotetext{
16. RODRÍGUEZ, 1553: 6 .

17. Ibídem.

18. RODRÍGUEZ, 1553: 7.

19. Petit-Breuilh, 2006: 136-140.

20. FUENTES Y GUZMÁN, 1969: 252.
}

Revista de Historia Moderna, n. ${ }^{\circ} 35$ (2017) (pp. 83-115) | ISSN-e: 1989-9823 | ISSN: 0212-5862 
solicitar de nuestros miserables obsequios y servicios, y solo pretende que se le expele la maldad, porque, en nosotros, halle disposición para reconciliarnos en su gracia y amor (...) entendiendo de cuanta eficacia y virtud sea la oración de los justos, e intercesión de los santos para negociar con Dios, a cuya instancia, muchas veces, el Soberano Señor ha tendido la mano, y la ejecución de su justicia (...) y esperamos firmemente que será defendida, y la ira de Dios finalmente mitigada ${ }^{21}$.

Sin duda, el mensaje que seguía repitiéndose en el mundo hispano durante las catástrofes era el de «aplacar la ira de Dios» mediante el sacrificio y la penitencia de la población. Asimismo, la erupción del Pichincha en 1575 es otro de los casos en que han quedado documentados los actos religiosos efectuados por procesos naturales. El suceso no era nuevo para los habitantes de Quito, pues desde la fundación de la ciudad habían experimentado varias erupciones del volcán vecino. Así al amanecer del día de la Natividad de Nuestra Señora (8 de septiembre), entre las seis y las siete de la mañana, los quiteños comenzaron a sentir fuertes ruidos subterráneos acompañados por sismos; pronto se escucharon explosiones formándose una densa columna eruptiva de forma que al precipitar la ceniza terminó oscureciéndose el día en la ciudad ${ }^{22}$. Los habitantes de Quito afligidos por la erupción del Pichincha se reunieron en la iglesia catedral y organizaron una procesión con la imagen de la Virgen; de esta forma los pobladores unidos en su «temor a Dios» caminaron descalzos pidiendo perdón por sus pecados en dirección hacia el Convento de la Merced, a pesar de la gran cantidad de ceniza que caía sobre la ciudad ${ }^{23}$. Al llegar a la iglesia conventual realizaron plegarias que incluían una misa, sermón y rezo de letanías con el fin de solicitar que se aclarara el día y que dejase de caer la ceniza sobre ellos, lo que sucedió en torno a las cuatro de la tarde; incluso durante la procesión ya comenzó a llover lo suficientemente fuerte como para limpiar la ceniza acumulada en los tejados evitando así que se hundieran. Al día siguiente amaneció despejado y los manantiales y fuentes recuperaron el

21. AMUNÁtegui, 1877: 432.

22. «Descripción y relación del estado eclesiástico del obispado de San Francisco de Quito», por Diego Rodríguez Docampo. Quito, 24 de marzo de 1650 en Relaciones geográficas de la Audiencia de Quito. Siglos XVI-XIX, 1992, tomo 2: 265-266.

23. «Descripción y relación del estado eclesiástico del obispado de San Francisco de Quito...», 1992, tomo 2: 265. 
agua que habían perdido. Desde luego, la coincidencia de las rogativas con el restablecimiento de la normalidad fue interpretada por los habitantes de Quito en el sentido de que sus súplicas y oraciones habían sido atendidas y, por tanto, consideraron este hecho como un milagro de la Virgen. Igualmente se refiere que los indígenas habrían quedado admirados al ver que los rezos, supuestamente, habían conseguido el objetivo que se pretendía; de ahí que esta experiencia pudiera haber servido para confirmarlos en la fe católica que los misioneros les enseñaban ${ }^{24}$.

Esta es una de las primeras ocasiones del siglo XVI hispanoamericano en la que se podría intuir un antecedente de la procesión de «sangre», ya que según los hechos documentados los vecinos de Quito se pusieron de acuerdo para caminar descalzos con objeto de pedir misericordia a Dios; lo expuesto anteriormente era una manera de hacer un sacrificio añadido a la rogativa, siguiendo el modelo de las procesiones más solemnes de la Semana Santa. Por su parte, las denominadas «procesiones de sangre» se comenzaron a realizar cuando las catástrofes eran de grandes magnitudes o cuando los procesos naturales que afectaban a la población se mantenían en el tiempo, tal como ocurría con los terremotos seguidos de varios meses de réplicas, las erupciones volcánicas y las sequías prolongadas. En estas ocasiones se recurrió a diferentes tipos de penitencias, que tenían como objetivo que el cuerpo sufriera y se mortificase hasta que derramase sangre, algo propio de la mentalidad de la sociedad contrarreformista que tenía sus raíces en siglos precedentes. Entre las penitencias más características que se incluían en este tipo de ceremonias se encuentran las siguientes: caminar en la procesión con un lazo en el cuello -signo de una humillación pública-, ponerse cadenas atadas al cuerpo, colocarse ceniza en la cara y en el cuerpo, utilizar cilicios de malla metálica y de otros materiales, darse con piedras en el pecho, caminar descalzo y vestirse con sacos; esta última conducta fue particularmente elegida por los más ricos de la ciudad para dar muestra de humildad en estos casos extremos.

En este contexto, siete años más tarde de la erupción sufrida por la ciudad de Quito en 1575 tuvieron que hacer frente nuevamente a los efectos de la explosiva actividad del volcán Pichincha; por ello, la población reaccionó ante

\section{Ibídem.}


el desastre organizando rogativas de «sangre», entre otros rituales. El escenario comenzó a crearse durante la mañana del 14 de junio de 1582 cuando se sintieron fuertes ruidos subterráneos acompañados de explosiones y sismos volcánicos; del mismo modo, se formó una densa columna eruptiva de la que fueron precipitando grandes cantidades de ceniza negra. Unas semanas después los habitantes creían superada la actividad eruptiva del Pichincha; sin embargo, este se reactivó nuevamente de forma que el 11 de julio comenzó a caer una abundante cantidad de piroclastos y agua sobre Quito (erupción freatomagmática), entre las tres y las cuatro de la tarde, situación que se mantuvo hasta el día siguiente. El 14 de julio por la tarde se reiniciaron las explosiones en el Pichincha formándose nuevamente una columna eruptiva densa y alta; además, a media noche se sintió en Quito un fuerte sismo acompañado de una considerable y ruidosa explosión que resultó ser una erupción vulcaniana que se mantuvo hasta el día siguiente ${ }^{25}$.

Sin duda lo que contribuyó al clima de desasosiego entre los vecinos de Quito fue el hecho de que esta erupción estuvo precedida de rumores y previsiones sobre el posible desastre que podría producirse tras la difusión de un augurio de los indígenas que pronosticaba la destrucción total de la ciudad; este hecho fue constatado y registrado documentalmente por Toribio de Ortiguera -alcalde de la localidad-, quien dejó testimonio de que días antes de tener lugar la erupción del Pichincha se comentaba en las calles que «el 15 de junio del año 1582 se hundiría la ciudad con un terremoto y temblor que habría de causar el volcán con mucho fuego y piedra que de sí echaría ${ }^{26}{ }_{»}$. Este pronóstico causó tanto miedo en algunas personas que tres o cuatro días antes del citado día 15 salieron huyendo de la ciudad más de la mitad de sus habitantes, lo que contribuyó a generar un gran desconcierto y temor en los que se quedaron.

Según el mencionado informe elaborado por el alcalde de Quito se trató por todos los medios de averiguar desde dónde había salido tal rumor con objeto de esclarecer la veracidad de la fuente; pero finalmente no pudieron encontrarse documentos o personas que desde la Ciudad de los Reyes ${ }^{27}$-lugar

25. ESTUPIÑÁN, 1998:36.

26. JIMÉNEZ DE LA ESPADA, 1965: 97.

27. Ciudad de los Reyes era la antigua denominación de Lima. 
desde donde se suponía había llegado el comentario- hubiesen traído la noticia de la inminente destrucción. A este respecto, el alcalde daba por cierto en su escrito que todo lo que se rumoreó en Quito fue un pronóstico realizado por algunos indios hechiceros de los alrededores de la ciudad ${ }^{28}$. Precisamente, en toda América se pueden registrar datos donde los nativos asumen que la «naturaleza se vengará de los conquistadores» a través de los elementos: agua, fuego, tierra y aire ${ }^{29}$.

El ambiente de intranquilidad que se generó en la población motivó que cuando el volcán Pichincha inició su actividad eruptiva el 14 de junio de 1582 la mayoría de los habitantes consideraron auténtico el rumor que había sido extendido y creyeron que realmente el fin de la ciudad estaba muy cerca; como consecuencia de ello se organizaron una serie de rituales para suplicar a Dios que no les enviara la destrucción al día siguiente, tal y como se había anunciado. De este modo, los vecinos que permanecieron en Quito realizaron plegarias, oraciones y un Vía Crucis; dentro de este marco de rogativas y de recogimiento espiritual visitaron las iglesias y monasterios durante el día y la noche, organizándose una procesión de disciplinantes con fuertes y repetidos toques de campanas.

Según el testimonio de Toribio de Ortiguera, los penitentes al comprobar con el paso de las horas que la magnitud de la erupción iba decayendo se sintieron aliviados y dieron gracias a Dios creyendo que sus súplicas habían sido atendidas por la divinidad, especialmente al comprobar que el 15 de junio -anunciado como la fecha de la destrucción- solo cayó algo de ceniza y agua sobre la ciudad antes de calmarse el volcán.

Un mes después, el 14 de julio de 1582 por la noche, al percibir los pobladores que el Pichincha estaba peligrosamente activo y lanzaba «piedras como nunca antes», les hizo recordar el augurio que advertía de la destrucción de Quito mediante «piedras» que echaría de sí el volcán. Ese mismo día los religiosos y seglares se congregaron para rezar algunas estaciones del Vía Crucis haciendo disciplinas «con gran devoción y temor de Dios». El hecho de que los fuertes sismos provocaran la mayor parte de los destrozos causados en la ciudad influyó en que los habitantes se encomendaran al abogado de

28. JIMÉNEZ DE LA ESPADA, 1965: 94.

29. Petit-Breuilh, 2006: 122-127. 
los temblores, «el bienaventurado San Jerónimo», para que intercediera ante Dios con el fin de que terminara con ellos ${ }^{30}$. Según las fuentes consultadas, los sismos disminuyeron casi de forma inmediata en frecuencia e intensidad, al tiempo que la actividad volcánica se fue calmando lentamente, que para entendimiento de los habitantes de la ciudad se debió a los rituales efectuados; de ahí que la propia mentalidad religiosa de los pobladores interpretara que sus sacrificios y oraciones posibilitaron que el Altísimo se apiadase de ellos y les perdonara sus pecados y, de este modo, pudieran conservar sus vidas.

Ciertamente, el clima y la geodinámica del Nuevo Mundo dieron múltiples oportunidades para que los hispanos tuvieran que recurrir repetidas veces a todas las fórmulas imaginables en la época para intentar resolver sus problemas de relación con el medio ambiente; de este modo, las sequías también fueron una importante razón para organizar rituales religiosos e invocar a mediadores de la corte celestial. Precisamente, fue en la ciudad de La Imperial -ubicada en el sur del Reino de Chile- donde se produjo una «gran seca» algunos años antes de 1600. Según las crónicas de la época, la falta de lluvia había llegado a un punto crítico, pues se habían esterilizado los campos e incluso se habían formado grietas en la tierra, motivo por el que los labradores no sabían si cosecharían algo ese año; para aumentar los males vino una peste de gusanos que cubría todo el suelo y que casi terminó con las raíces de lo poco que había germinado. Ante esta situación crítica las autoridades del asentamiento convocaron a los vecinos a cabildo abierto; en dicha reunión decidieron sacar de la iglesia mayor a la devota imagen de Nuestra Señora de las Nieves, a quien le cantaron una misa y le hicieron alabanzas; una vez que los habitantes asistieron a la misa y mientras que llevaban la imagen en procesión de regreso - «abrasados todos de calor»-comenzó a llover con gran fuerza. El suceso fue descrito así por el jesuita Alonso de Ovalle:

(...) se entoldo de repente, y comenzó a llover con tanta fuerza, que fue menester, para que la imagen no se mojase, que se quitasen algunos las capas, para cubrir con ellas las andas, en que la llevaban; y de esta manera acabaron la Procesión, y el agua prosiguió, con un gran tesón, dos días enteros, con

30. «Descripción y relación del estado eclesiástico del Obispado de San Francisco de Quito por Diego Rodríguez Docampo. Quito, 24 de marzo de 1650» en JIMÉNEZ DE LA ESPADA, 1888, tomo III: 71. 
sus noches: con que no quedó gusano vivo, y la tierra se fertilizó de manera, que nunca dio mas pan, ni mas abundantes cosechas, que aquel año ${ }^{31}$.

Desde luego, este tipo de experiencias convertidas en tradición hizo que la devoción a ciertas imágenes fuera aumentando en distintos lugares del continente americano.

Por su parte el siglo XVI finalizó con uno de los escenarios más dantescos que se vivieron en América durante la época colonial; se trató de la erupción del volcán Huaynaputina (Perú) ${ }^{32}$. En esta ocasión una de las ciudades más afectadas por la actividad explosiva fue Arequipa ${ }^{33}$, lugar desde donde se escribieron la mayoría de los testimonios que se conocen de este suceso catastrófico. Atendiendo a las informaciones proporcionadas por las fuentes, la población de los alrededores del volcán comenzó a sentir sismos de baja intensidad desde los días $14^{34}$ ó 15 de febrero de 1600, lo que se intensificó el 18 de este mes ${ }^{35}$ y lo que inicialmente fue una curiosidad, sobre todo la caída de una blanca pómez, pasó a transformarse en miedo y angustia al ver que la ceniza volcánica y los sismos no cesaban ${ }^{36}$. Precisamente, es sabido que para cualquier católico de la época tener una «buena muerte» era una de las aspiraciones fundamentales y, por tanto, se consideraba que los que fallecían repentinamente sin estar preparados espiritualmente, es decir, sin haber recibido los sacramentos de la confesión y de la comunión tendrían dificultades para alcanzar la salvación de sus almas. A este respecto, el comportamiento desesperado de los habitantes de Arequipa para obtener

31. OVALLE, 1646: 186.

32. Petit-Breuilh, 25 (2016): 1-26.

33. Precisamente desde Arequipa se realizaron las descripciones más completas de lo ocurrido durante la erupción, tanto de los efectos y daños producidos en la propia ciudad como en los pueblos de indios cercanos.

34. CALANCHA y TORRES, 1972: tomo 2: 78.

35. «Relación de la erupción del volcán Huaynaputina por Pedro de Vivar, soldado de las guardias de Castilla de su Magestad que se halló presente en la ciudad de Arequipa», en VÁsQueZ DE ESPINOZA, Antonio, Compendio y descripción de las Indias Occidentales (segunda década del siglo XVI). Manuscrito, f. 87r. BAV. Barb. lat. 3584. Por su parte, el fraile agustino Diego de Ocaña escribió sobre esta erupción basándose en el relato del contador de la Hacienda Real Sebastián de Mosquera, entre otras personas, en OCAÑA, 1987: 206-207 y ss.

36. MURÚA, 1987: 539. 
el sacramento de la confesión a medida que aumentaban las explosiones del volcán es una consecuencia de ese tipo de mentalidad; esas reacciones y conductas aparte del miedo a la muerte se podrían explicar por el temor que tenían las personas de no estar suficientemente preparadas para afrontar el paso de esta vida a la otra, en la que se pretendía lograr la eternidad junto a Dios. Uno de los múltiples relatos de esta erupción describe gráficamente alguna de estas situaciones vividas por los arequipenses durante los rituales que organizaron:

Y comenzaron a hacer algunas procesiones y a pedir a Dios misericordia, (...) y se hizo una procesión de sangre en la cual iban todos descalzos, así frailes como seglares, todos con reliquias en las manos porque cada uno tomaba aquello con que más devoción tenía (...) tantas cadenas, tantos grillos, tantos hombres aspados, tantas penitencias y tan áspera hubo en esta procesión cuanto jamás se ha visto en el mundo ${ }^{37}$.

En este ambiente, las procesiones se repitieron durante los días de mayor caída de ceniza, buscando los religiosos junto al corregidor de Arequipa «aplacar la ira de Dios» ${ }^{38}$. Estas ceremonias típicamente barrocas intentaban obtener la misericordia divina por medio de rituales públicos como las rogativas y las penitencias de sangre, puesto que eran producto de un sentimiento colectivo y dramático del pecado. Lo anteriormente expuesto concordaba con la mentalidad de personas que vivían bastante preocupadas por un conjunto de apariencias, en las que los rituales públicos ofrecían la oportunidad de dejar claro a los demás el lugar que cada una de ellas ocupaban en la sociedad, al tiempo que dejaban en evidencia supuestas virtudes de bondad y religiosidad que se trataban de demostrar ante los integrantes de la comunidad ${ }^{39}$.

Sin duda, mediante el análisis de los comportamientos de los colectivos sociales afectados por la ruina de Arequipa y alrededores tras la erupción del volcán Huaynaputina de 1600 se pone de manifiesto que sus vidas estaban sujetas a vulnerabilidades y, por otra parte, queda claro el carácter providencialista que se le asignaba a la mayoría de las actividades humanas; realmente

37. OCAÑA, 1987: 207.

38. Petit-Breuilh, 25 (2016): 9-16.

39. ÁlVAREZ SANTALÓ, 1989: 529-532.

Revista de Historia Moderna, n. ${ }^{\circ} 35$ (2017) (pp. 83-115) | ISSN-e: 1989-9823 | ISSN: 0212-5862 
esta idea era una herencia de la mentalidad medieval exportada y perfeccionada en la América de los siglos XVI y XVII.

Ciertamente, no solo los terremotos y las erupciones volcánicas motivaron a los hispanos a realizar toda esta gama de rituales, puesto que en otros procesos naturales menos inmediatos y drásticos también se practicaban, aunque hayan quedado menos documentados. En este sentido, se sabe a través de variadas fuentes históricas que las grandes sequías del siglo XVII impulsaron a la población de la zona central de Chile para realizar procesiones rogativas con el fin de combatirlas. El jesuita Alonso de Ovalle señaló en su obra que durante los primeros años del Seiscientos los habitantes de la Ligua le pidieron la mediación divina a la imagen de Nuestra Señora de las Nieves para que terminara con una prolongada sequía, cuya talla había sido llevada a la localidad después del sitio de las ciudades del Sur ${ }^{40}$; según el mencionado cronista, el maestre de campo Pedro de Ybacache «dispuso hacer una fiesta a esta santa imagen, y que se le cantase una misa con su procesión ${ }^{41}$. Seguramente se tomó esta decisión debido a la fama que tenía esta advocación cuando escaseaba la lluvia, pues sus «milagros» eran conocidos; así, la convicción en los poderes sobrenaturales de esta Virgen aumentaría entre los pobladores si se atiende al testimonio ofrecido por el citado Alonso de Ovalle:

(...) comenzó a llover tan deveras, que fue necesario, que se quitasen las capas lo que ivan en la procesión para cubrir la Santa imagen, para que no se mojase: entrándola en su capilla, prosiguió el aguacero, a descargar con tal fuerza que corrian arroyos de agua por los campos, de manera que los combidados no pudieron volver tan presto a sus estancias: duró el agua todo lo que bastó para bañar la tierra, y disponerla para las buenas cosechas ${ }^{42}$.

40. Se refiere al alzamiento general que iniciaron los araucanos en 1598 y que terminó alrededor de 1602 con la destrucción de todas las ciudades fundadas por los españoles al sur del río Bíobío.

41. Ovalle, 1646: 188.

42. Ibídem. 


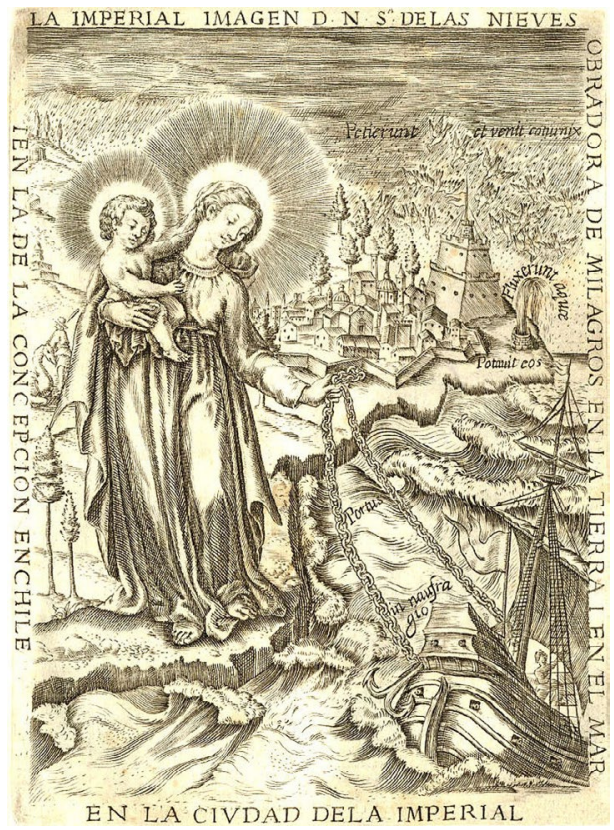

Figura 1: Dibujo de la Virgen de las Nieves a la que se atribuyó varios milagros en el siglo XVI y XVII en el Reino de Chile ${ }^{43}$.

Precisamente, otra de las sequías más intensas que afectó a la ciudad de Santiago de Chile y sus alrededores fue la que se inició en 1637 y que llegó a su clímax en junio de 1640; a propósito de este suceso no se han encontrado descripciones de las procesiones realizadas, pero de todas maneras está claro que la Virgen de la Merced ya había sido nombrada hacia finales del siglo XVI como protectora ante este fenómeno natural, lo que indicaría iniciativas religiosas en ese sentido.

Por su parte, las inundaciones también motivaron la organización de estos rituales, como lo demuestran los desarrollados en la ciudad de México en 1629 , después de una de sus peores crecidas. Según la documentación disponible, «el 21 de septiembre de ese año se experimentó el máximo de agua caída, que incluso superó las defensas de tierra y piedras llamadas albarradas

43. Ovalle, 1646: 204.

Revista de Historia Moderna, n. 35 (2017) (pp. 83-115) | ISSN-e: 1989-9823 | ISSN: 0212-5862 
que se habían construido para proteger las calles» ${ }^{44}$. A causa del natural desconsuelo que generó esta situación, los habitantes que se mantuvieron en la ciudad a pesar del desastre, organizaron rogativas y oraciones. Por iniciativa del arzobispo de México se trasladó la imagen de la Virgen de Guadalupe a la catedral para que los feligreses pudieran rezarle; del mismo modo, los dominicos realizaron varias procesiones con la Virgen del Rosario ${ }^{45}$. Una vez que dejó de llover y descendió el nivel de las aguas regresó la normalidad, lo que se interpretó como un milagro de la Virgen de Guadalupe. A este respecto, Francisco López de Gómara explicaba: «Llovía tanto en año $28^{46}$, que se perdían los panes y ganado, y hasta las casas. Hicieron procesión y oraciones en Méjico, Tezcuco y otros pueblos, y cesaron las lluvias; que fue gran confirmación de la fe» ${ }^{47}$.

Si nos detenemos a analizar la participación que hasta entonces estaban teniendo los indígenas en este tipo de ceremonias organizadas por los hispanos podría decirse que poco a poco iban asumiendo la ritualidad cristiana, según los datos aportados por Francisco López de Gómara. En este sentido, el cronista señaló que se adhirieron muy pronto al sacramento del bautismo y asistieron con entusiasmo a rezar en los templos; algo más complicado fue conseguir que se confesaran. Por otra parte, en el caso de la Nueva España los nativos participaron activamente en las disciplinas de Semana Santa y en las procesiones de sangre en casos de procesos naturales catastróficos, si nos atenemos a los comentarios del citado López de Gómara: «La disciplina y penitencia de azotes la tomaron pronto y mucho, con la costumbre que tenían de sangrarse a menudo por devoción, para ofrecer su sangre a los ídolos; y así, acontece ir en una procesión diez mil, cincuenta mil, y hasta cien mil disciplinantes. Todos en fin se disciplinan de buena gana, y mueren por ello (...) se suelen azotar en las espaldas, cosa muy natural $(\ldots) »^{48}$.

44. Colección de Memorias de Nueva España, «Gran inundación que padeció la ciudad de México». Archivo de la Real Academia de la Historia (ARAH)-Colección Boturini, 9/4857, f. 79 .

45. Ibídem: f. 82.

46. Será una confusión de fechas, pues la gran inundación de ciudad de México ocurrió en 1629 , antes de hacerse las obras de desecación de parte del lago.

47. LÓPEZ DE GÓMARA, 1966: 434.

48. Ibídem: 432. 
Seguramente, cuando los habitantes de los pueblos originarios observaban las manifestaciones barrocas de las procesiones rogativas se sentirían en sintonía con estas costumbres, pues para ellos resultaba normal ofrecer sangre a sus dioses, sobre todo cuando se les iba a pedir un favor importante. Sin embargo, los misioneros que conocían sus antiguas tradiciones observaron con preocupación este tipo de expresiones tan entusiastas, pues les quedaba la duda de que si realmente lo hacían por devoción al Dios cristiano o como una vía de retorno a sus antiguas sangrías en honor a sus dioses ancestrales; en este sentido, López de Gómara agregaba lo siguiente: «Bueno está que se disciplinen en remembranza de los muchos azotes que dieron a nuestro buen Jesús, pero no que parezca recaer en sus viejas sangrías, y por eso algunos se lo quieren quitar, o al menos templar» ${ }^{49}$.

Con todo, si se hicieron intentos para minimizar este tipo de expresiones religiosas se puede decir -sobre la base de la documentación de toda la segunda mitad del siglo XVII- que las rogativas de sangre se siguieron realizando en distintos lugares de Hispanoamérica, especialmente durante procesos naturales con características de desastre como lo fueron terremotos de gran magnitud.

Con respecto a las rogativas de mediados del siglo XVII puede decirse que eran rituales totalmente organizados y que constituían actos públicos donde la ubicación de los participantes dependía del rango; sin duda, eran momentos para que los asistentes fueran vistos por los demás, lo que creó más de algún altercado debido a la posición que cada autoridad estimaba que le correspondía. En este sentido, el tema del protocolo que era aplicado durante estas ceremonias resultaba ser en la época un asunto de Estado, por ello no es extraño confirmar en las fuentes históricas que el rey y el Consejo de Indias tuvieron que legislar sobre este asunto para que no se produjeran situaciones bochornosas. Precisamente, los altercados daban paso a polémicas y rivalidades entre las autoridades civiles y eclesiásticas que no eran un buen ejemplo para la ciudadanía ${ }^{50}$.

49. Ibídem.

50. «Real Cédula sobre precedencia en las procesiones y otros actos y sobre varios puntos del ceremonial, 10 de julio de 1636» en LiZANA, 1920: 563-564. 
Ante este panorama la rogativa pública se había transformado en una respuesta conocida para afrontar los males que acosaban a la sociedad barroca del siglo XVII, siendo totalmente consecuentes con la mentalidad providencialista que se imponía lenta y progresivamente.

Atendiendo a las catástrofes naturales analizadas hasta mediados del siglo XVII, los terremotos o crisis sísmicas eran los procesos que más intranquilizaban a la población debido a la percepción de que no existían sitios seguros, principalmente porque se desconocía el verdadero radio de acción de estos fenómenos; en este sentido, las conductas vinculadas a las inundaciones o erupciones volcánicas eran diferentes, ya que respecto a estos eventos se tenía más claro el foco del peligro. En este contexto, en 1642 durante una crisis sísmica que duró varios días en Guatemala se realizaron una serie de rituales para invocar a Dios con objeto de que no se destruyera la ciudad; el misionero Tomás Gage lo expresó de este modo: «los habitantes abandonaron sus casas por espacio de nueve días por temor de la muerte que les amenazaba a causa de los repetidos temblores, y se retiraron a la plaza del mercado bajo de tiendas y barracas a donde se hicieron transportar las imágenes de los santos, y entre otras la de San Sebastián, que también llevaron en procesión dentro de la ciudad $»^{51}$. Es evidente que la primera ruina de Santiago de los Caballeros en 1541 todavía estaba presente en el imaginario colectivo de los hispanos y destaca el afán de los habitantes de Guatemala de poner a resguardo a las imágenes de sus santos patronos a quienes pidieron intercesión ante Dios.

Por su parte, los santiaguinos de Chile hicieron lo suyo después del devastador terremoto del 13 de mayo de $1647^{52}$. Como respuesta a lo que ocurría, los habitantes de la ciudad organizaron dos procesiones que recorrieron las calles del centro, llegando después a la Plaza Mayor; una de ellas partió de la iglesia de San Francisco y la otra desde la de San Agustín. Según el relato del obispo Villarroel los hechos ocurrieron del siguiente modo:

Trajeron los padres de San Francisco, la imagen de Nuestra Señora del Socorro $^{53}$ que ha hecho en esta ciudad muchos milagros. Vinieron azotándose

51. GAGE, 1838: 14.

52. PALACiOS, 2015: 62-94.

53. El obispo Villarroel se refiere a la imagen que Pedro de Valdivia llevó consigo a Chile y que aún existe en el altar mayor de la iglesia de San Francisco. 
los religiosos, y de ellos un lego haciendo actos de contrición con tanto espíritu y tan bien formado, que yo, como aprendiz en la escuela de la devoción, iba repitiendo lo que él decía. Movió mucho al pueblo este espectáculo; y aunque creció el arrepentimiento, no pudo decrecer el susto, porque temblaba la tierra a cada rato $(\ldots)^{54}$.

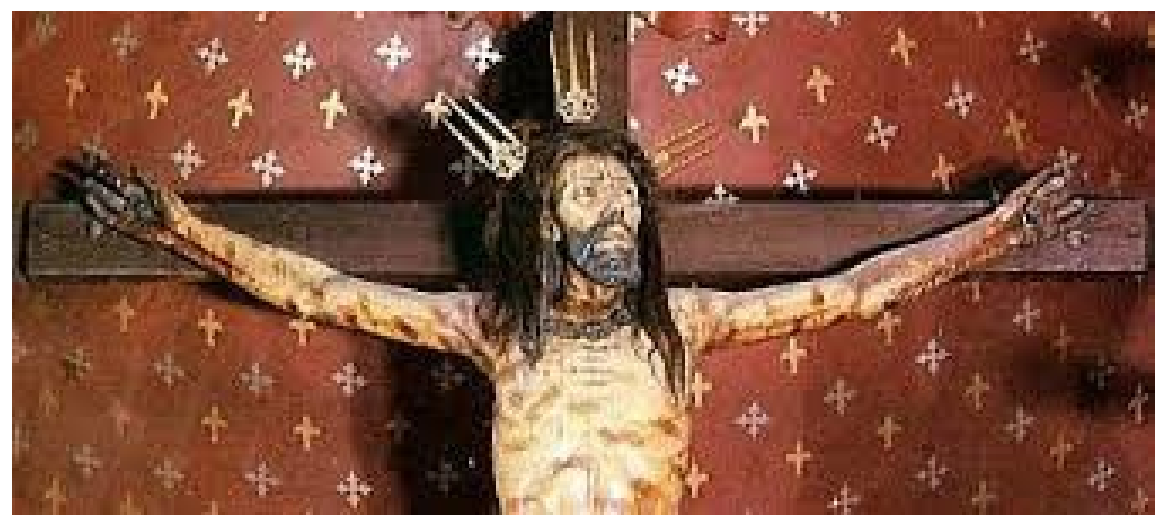

Figura 2. Parte de la talla del «Cristo de Mayo» donde destaca la corona de espinas en su cuello tras el terremoto de 1647 . La leyenda dice que si se intenta colocar la corona en su sitio volverá a temblar.

Los padres de San Agustín salieron desde su iglesia con la segunda procesión encabezada por un devotísimo crucifijo llamado hasta ese entonces como el Señor de la Agonía, que se había salvado de la ruina y que había quedado con la corona de espinas en la garganta, hecho que estimaron como un prodigio. Por este motivo, conmovido el pueblo con su antigua devoción y el supuesto milagro, lo llevaron en procesión hasta la plaza, transformándose desde ese entonces en el «Señor de Mayo». En concreto, los religiosos y el obispo iban descalzos y avanzaban con grandes clamores, muchas lágrimas y «universales gemidos» ${ }^{55}$.

Sin duda, en estos momentos de desolación la población se volcaba con sus devociones más queridas; por ello, no es extraño que invocaran a la

54. AMUNÁTEGUI, 1882: 318.

55. Ibídem: 319. 
Virgen del Socorro, puesto que había sido nombrada en abril de 1645 como patrona de la ciudad. Igualmente, el prodigio narrado de la imagen del Cristo de Mayo fue suficiente para que desde entonces se le tuviera especial fe en casos de terremotos y otras calamidades públicas. Por su parte, el obispo de Santiago dejó testimonio de las acciones adoptadas por los supervivientes un día después del suceso en los siguientes términos:

Desde que amaneció el 14 de mayo, se dijeron sucesivamente gran cantidad de misas en el altar de la Plaza, y se dio la comunión a una multitud de individuos de ambos sexos. Todos los que estaban enemistados se reconciliaron, y se pidieron mutuamente perdón. Los que vivían en relaciones ilícitas, y podían casarse, prometieron regularizar su situación, y realmente fueron efectuándolo así, a medida que las circunstancias se lo permitieron. Desde el 14 de mayo, hasta el 9 de junio siguiente, se verificaron más de doscientos matrimonios ${ }^{56}$.

Este relato incide en cuestiones expresadas con anterioridad en el sentido de que las situaciones de crisis servían para que los hispanoamericanos de los siglos XVI y XVII se pusieran al día en cuanto a la práctica de los sacramentos; en particular los de la confesión, la comunión y el matrimonio. Por otra parte, algunas de las penitencias realizadas durante las procesiones de «sangre» podían llegar a ser terribles si se atiende a lo que ocurrió en Potosí durante las rogativas que se hicieron como consecuencia del terremoto que asoló Cuzco y su entorno el 31 de marzo de $1650^{57}$. A este respecto señaló fray Diego de Mendoza: «Tan generales fueron las rogativas en todo el Perú por estos temblores, que no quedó ciudad, ni villa en que no se hicieron procesiones, especialmente en Potosí, donde fueron tales y tan ásperas las penitencias que algunos murieron en ellas ${ }^{58}$.

Atendiendo a lo expresado anteriormente, este tipo de comportamientos hispanos parecía muy consecuente con la cosmovisión indígena, debido a que los rituales buscaban el mismo fin que los ancestrales sacrificios humanos y de animales y aves propios de las antiguas tradiciones prehispánicas;

56. Ibídem: 320-321.

57. Verdadera relación del Gran Temblor y terremoto que Dios N. Señor fue servido de embiar a la Ciudad del Cuzco, a 31 del mes de Marzo (...) de 1650. México, Viuda de Bernardo Calderón, 1650.

58. ESQUIVEL Y NAVIA, 1986: 96 
en este sentido, en esa época ambos colectivos tenían la convicción de que una ofrenda de sangre era más considerada por la divinidad que otros gestos. Precisamente, los indígenas de diversas localidades americanas llegaron a realizar prácticas de sangre tan excesivas durante las procesiones rogativas y la Semana Santa que algunos funcionarios de la Corona y misioneros llegaron a pensar que este tipo de fanatismo no era otra cosa que una vuelta a sus antiguas tradiciones paganas; este es uno de los motivos que originó que desde finales del siglo XVII se recomendara que los mestizos e indios no efectuasen sacrificios desproporcionados.

Como se ha dicho con anterioridad, la intensidad de las manifestaciones religiosas dependía de la magnitud del desastre; este es uno de los motivos por los que durante las sequías no se experimentaron, en general, expresiones de tintes tan dramáticos y desesperados como en el caso de terremotos o erupciones volcánicas. De ello es ejemplo que el 29 de julio de 1656, la falta de lluvias para las siembras y «yerbas del campo» llevó al cabildo de Santiago a organizar una novena a la Virgen en el convento de Nuestra Señora de la Merced y finalizando la rogativa con una procesión hasta la catedral ${ }^{59}$. Como en otras ocasiones la decisión era tomada por la autoridad civil y comunicada a las autoridades eclesiásticas correspondientes para actuar en conjunto por el bien de la comunidad.

Pasando al análisis de otro proceso natural que terminó en desastre nos permite apreciar las expresiones religiosas de los hispanos ante la explosiva y catastrófica erupción del volcán Pichincha (Ecuador) en octubre de 1660. Además, para completar el panorama de crisis que se vivió en Quito y en sus alrededores se produjo el derrumbe de una parte del volcán Sincholagua como consecuencia de los fuertes sismos que acompañaron la erupción del Pichincha, lo que aumentó de este modo el impacto negativo en los habitantes y en el entorno. En este contexto de destrucción que se desató en la ciudad de Quito, la reacción inmediata de sus vecinos fue la de acudir a las iglesias para confesarse ${ }^{60}$; una vez congregados en ellas se hicieron misas para

59. Actas del Cabildo de Santiago de Chile en MEDINA, tomo XXXV, 1908: 197.

60. A propósito de las confesiones multitudinarias que se produjeron por el desastre el relato de Manuel Rodríguez expresaba lo siguiente: «Veinte fueron los que en el Colegio de la Compañía estaban en los confesionarios, y muchos del concurso no esperaban su vez, de poderse confesar, diciendo a voces sus pecados; y los gritos, lágrimas, sollozos 
invocar la «clemencia divina». Con posterioridad, los miembros de la Real Audiencia junto con el obispo se reunieron para organizar una procesión de sangre encabezada por el Santísimo Sacramento y la imagen de la Virgen de Copacabana -abogada de la ciudad-; el recorrido terminó en la iglesia mayor donde se inició una novena dedicada a la Virgen de Guápulo que había sido transportada solemnemente desde su pueblo, ubicado a unos dos kilómetros y medio, con el fin de amparar a los quiteños ${ }^{61}$. Una vez finalizado el ceremonial se trasladaron todos juntos al convento de la Merced, puesto que allí se encontraba una talla antigua de la Virgen situada en medio del tabernáculo del altar mayor. Esta imagen estaba hecha en piedra y representaba la advocación a la que la ciudad había realizado un voto en 1575 para protegerse ante las erupciones del Pichincha; por este motivo, la sacaron de su altar y la llevaron en procesión fuera de la iglesia con objeto de enfrentarla al volcán ${ }^{62}$. Sin embargo, después de realizados estos rituales, al mediodía del 27 de octubre, se produjo en el volcán una «nube ardiente» que se precipitó sobre la ciudad. Sobre este hecho catastrófico existen referencias en las Actas Capitulares de Quito del año 1660:

Añadióse a la tiniebla otra más tupida confusión de horrores en la celeste esfera de una preñada nube, que reventando víbora articulada de incendios en rotas señales de relámpagos abortó en estruendos de truenos muchos rayos, con que bramando en monte ... en la tempestad, los aires parecían dos ... distantes ejércitos ${ }^{63}$.

Algunos detalles relacionados con los rituales se encuentran en las Cartas Annuas de Quito de 1660, donde se registró que en el iglesia de la Compañía de Jesús: «descubrióse el Santisimo Sacramento, tocose a plegaria, y lo mismo hicieron las demás iglesias», donde se agrega un dato muy interesante: «se

y suspiros de todos causaban grande confusión, y obligaba a dar absoluciones luego, que había materia de pecado confesado y propósito de la integridad (...) Allí se oían los votos y promesas fervorosas, se daban bofetadas, se mesaban los cabellos en señal de penitencia y arrepentimiento de sus culpas, sin que persona alguna se acordase de otra cosa que de prevenir para la muerte». ESTUPIÑ́N, 1998: 51-52.

61. Ibídem: 54.

62. «Informe de la Real Audiencia al Rey de España sobre la erupción del Pichincha» en ESTUPIÑÁN, 1998: 45.

63. Libro del Cabildo de Quito, 1660 en EstuPIÑÁN, 1998: 175. 
predicó en lengua española y también en la de Hinga ${ }^{64}$, o sea, en quechua. Es evidente que el repique de campanas indica una forma de conjuro por la creencia de que posibles fuerzas malignas pudieran estar detrás del desastre y el hecho de que los sermones fueran platicados en ambos idiomas señala que una parte de la población de Quito, aún en esas fechas del siglo XVII no entendía el castellano y los misioneros eran conscientes de esa realidad.

Como consecuencia de la abundante caída de cenizas del día anterior, el 28 de octubre amaneció tenebroso y ceniciento. Esta situación se agravó debido a la formación de un nuevo flujo de piroclastos que se depositó esta vez en la región de los indios yumbos y del volcán Sincholagua; precisamente un lugar que frecuentemente había sido afectado por las erupciones del Pichincha durante el siglo XVI. Como requería el desastre que estaba afectando a la ciudad de Quito y alrededores se efectuaron varias procesiones de sangre con gran asistencia de «la gente secular, y de mucho concurso de indios» ${ }^{65}$. Según los relatos de la época, se hicieron duras penitencias: unos iban en las procesiones con grillos y cadenas, otros aspados y ceñidos estrechamente de cilicios, otros se daban latigazos en distintas partes del cuerpo para sacarse sangre y otros llevaban pesadas cruces $^{66}$.

Tras la actividad explosiva generada por el Pichincha el 28 de octubre, los días posteriores se sucedieron entre pardos y nublados hasta el uno de noviembre de $1660^{67}$; fecha en que se repitieron las confesiones públicas, las rogativas y las misas con la intención de que terminara el desastre de forma definitiva. Unas semanas más tarde -a pesar de los rezos, rogativas y conjuros organizados por los vecinos de Quito-, el 28 de noviembre de 1660 el Pichincha aumentó su actividad explosiva durante la madrugada formando una densa columna eruptiva que terminó precipitando abundante ceniza sobre Quito; finalmente el día se aclaró y la erupción fue decreciendo en intensidad a medida que transcurrían las jornadas. En diciembre de 1661 y

64. Cartas Annuas, Nuevo Reino de Quito, 131, f. 33r. Archivo ARSIS.

65. Cartas Annuas, Nuevo Reino de Quito, 131, f. 33r, ARSI. Manuel Rodríguez citado por ESTUPIÑÁN, 1998: 54.

66. Cartas Annuas, Nuevo Reino de Quito, 131, f. 33r-33v, ARSI.

67. ESTUPIÑÁN, 1998: 180. 
el uno enero de 1662 se sintieron fuertes terremotos en Quito ${ }^{68}$, que fueron relacionados con algunos derrumbes que ocurrieron en el cráter del volcán Pichincha una vez que terminó la erupción; por esta razón, se volvieron a organizar procesiones, rogativas y sacrificios para pedir a Dios que se terminaran los desastres en la ciudad utilizándose como mediadora a la Virgen de Guápulo ${ }^{69}$.

Un año más tarde, en la ciudad de México, los habitantes se echaron a la calle pidiendo misericordia a Dios para que se terminara una erupción del Popocatepetl que se inició el 13 de octubre de 1663; la actividad no fue especialmente explosiva pero se mantuvo hasta 1667. Según fray Agustín de Vetancurt en su obra Teatro Mexicano, como consecuencia de la permanencia de la erupción durante el año 1664 los pobladores organizaron «procesiones rogativas y de sangre, pidiendo á Dios misericordia, porque la ceniza era en cantidad, y con ella piedras que se hallaban menudas, livianas como de piedra-pómez» ${ }^{70}$; además realizaron otros rituales como misas, rezo de letanías y sermones.

Sin duda, el aumento de la población de las ciudades y el campo durante el Seiscientos hacía cada vez más dependientes a las comunidades de sus producciones agrícolas; en este sentido, las lluvias torrenciales o las sequías determinaban la calidad de vida de las familias en ciertas épocas. En este contexto, Benjamín Vicuña Mackenna dejó documentado que la zona central de Chile «fue solo una procesión de calamitosas secas, seguidas de otras tantas procesiones a santos pero ingratos e implacables abogados ${ }^{71}$, especialmente durante la segunda mitad del siglo XVII. De igual modo, con posterioridad al terremoto que destruyó Lima en 1687 se realizaron todo tipo de rituales; ciertamente las fuentes de la época reseñan confesiones públicas, sermones y una serie de procesiones rogativas que se repitieron durante varios días ${ }^{72}$.

68. Real Cédula, 10 de julio de 1664. Buen Retiro. Archivo General de Indias (AGI), Quito, 210. L.4, f. 24r.

69. AGI, Quito, 210. L. 4, f. 24v. Para más detalles de esta advocación ver PETIT-BREUILH, 2007:226.

70. VETANCURT, 1698: 77-78.

71. ViCUÑA MACKENNA, 1877: 44.

72. «Relación de los Terremotos ocurridos en la ciudad de Lima el 20 de octubre de 1687 ». ARAH, Fondo Salazar y Castro, Ms. 1026, N-54, f. 27. 
Por su parte, uno de los últimos episodios catastróficos del siglo XVII fue la erupción explosiva del volcán Cotopaxi (Ecuador) que se inició a mediados de 1698. En esta ocasión el desastre se extendió territorialmente debido a que junto con la fase paroxismal se produjo un fuerte terremoto que a su vez desencadenó el derrumbe de una parte del volcán Carguairazo (Ecuador) ${ }^{73}$. Como consecuencia de este derrumbe se formó un flujo de detritos voluminoso que se depositó violentamente en los pueblos del valle sobre una extensión de cerca de $36 \mathrm{~km}^{274}$, afectando especialmente a las localidades de Ambato y Latacunga. En la erupción de 1698 la conjunción de procesos naturales catastróficos, deben estudiarse relacionados -erupción, terremoto y derrumbe-, ya que afectaron negativamente a la población de Quito y a sus alrededores sumando las situaciones de desastre y, por tanto, creando las condiciones necesarias para que las expresiones colectivas afloraran como en otros desastres anteriores.

Sin duda son variados los ejemplos de procesos naturales que llevaron a la población de los siglos XVI y XVII en la América hispana a elevar sus plegarias a la divinidad y a realizar todo tipo de rituales y ceremonias para aplacar la «ira de Dios», especialmente procesiones con diversos matices: rogativas, de sangre o de acción de gracias.

\section{Reflexiones finales}

Después de haber analizado esta secuencia de catástrofes ocasionadas por distintos procesos naturales en América como sequías, terremotos y erupciones volcánicas, puede plantearse que comparando el siglo XVII con el anterior las respuestas colectivas ante los desastres fueron haciéndose cada vez más organizadas y estructuradas. Hasta tal punto fue así que en la mayoría de los casos esta coordinación fue dirigida por la propia Corona mediante reales

73. El volcán Carguairazo está situado junto al Chimborazo y cercano al Tungurahua. El derrumbe de junio de 1698 quedó registrado en 1748 por Jorge Juan y Antonio de Ulloa como una erupción volcánica del Carguairazo; sin embargo, según las evidencias geológicas e históricas es un error. Seguramente lo que se produjo fue una remoción en masa como la que tuvo lugar en el volcán Agua (Guatemala) en 1541 o en el volcán Sincholagua (Ecuador) en 1660, que ya han sido analizadas en el transcurso de esta investigación.

74. BARROS ARANA, 1871: 79. 
cédulas en las que se especificaban, entre otras cuestiones, la necesidad de hacer rogativas públicas; estas normas buscaban la finalidad de que las invocaciones a la divinidad regularan, entre otras cuestiones, la ubicación de cada participante en las procesiones según el sistema jerárquico impuesto por las autoridades peninsulares. De esta manera, se trataba de poner orden en las constantes pugnas de poder que existían entre los miembros civiles y eclesiásticos de las distintas jurisdicciones coloniales ${ }^{75}$.

Por otro lado, si se considera que en la América hispana convivían las ideas providencialistas de indígenas e hispanos, a pesar de que ambos disponían de un panteón diferenciado, no deja de ser un punto de encuentro entre ellos; a este respecto, los dos grupos étnicos creían que eran los dioses los que enviaban los desastres como señal o como castigo por los pecados cometidos. No en vano en las Cartas Annuas de Quito se expresaba en 1660: «los bramidos del Pichincha fueron voces de Dios que despertaron las almas del letargo en que miserablemente iacían las personas ${ }^{76}$. Así, la relación de la sociedad en esta época con los elementos de la Naturaleza servía como modelo edificante que fue utilizado por la propaganda de la Corona y de la Iglesia católica para resolver el desconocimiento que se tenía sobre el origen real de los procesos naturales y mantener las costumbres cristianas entre los súbditos españoles. No se plantea que fuera una estrategia maquiavélica, sino que en aquel tiempo esta solución resolvía ese vacío de razón y entregaba un discurso verosímil que calmaba las conciencias de la población. Toda esta valoración nos lleva a pensar que a veces el aparente desinterés del hombre como especie frente a su cotidianeidad lo enfrentaba ante estas situaciones de crisis que trastocaban todo y lo hacía replantearse su vida y la de sus seres queridos y en extensión, de la sociedad en su conjunto; aunque la reiteración de estos comportamientos en el largo período también deja en evidencia que los cambios no eran permanentes en el tiempo ya que cuando ocurría otro desastre, el panorama volvía a ser sustancialmente el mismo.

Sin duda, esta confluencia de ideas es fundamental para entender el desarrollo de los rituales religiosos en el Nuevo Mundo durante los siglos XVI y

75. «Real Cédula sobre precedencia en las procesiones y otros actos y sobre varios puntos del ceremonial, 10 de julio de 1636», LIZANA, 1920: 263-265.

76. Cartas Annuas, Nuevo Reino de Quito, 131, f. 34r-34v, ARSI. 
XVII. En este sentido, la tesis providencialista promovida por la Corona y la Iglesia se fue introduciendo paulatinamente en el discurso propagandístico que se dirigía también a los indígenas, quienes resultaron ser buena tierra de cultivo para este pensamiento; no en vano, desde la época prehispánica estimaban, de igual manera que los cristianos, que los males de la humanidad eran causados por la «ira» de los dioses.

En este marco de creencias, las manifestaciones religiosas demuestran que en la América del siglo XVII se impusieron rápidamente las expresiones barrocas y se fue consolidando el sincretismo que se estuvo fraguando desde los primeros años de contacto entre lo hispano y lo indígena; de ahí que las rogativas, las penitencias, las procesiones de sangre, los exorcismos y conjuros destinados a los elementos naturales quedasen marcados por la mentalidad contrarreformista.

Atendiendo al conjunto de situaciones de procesos naturales que superaron la capacidad de respuesta de su población en esta época de estudio, parece desprenderse que cuando coincidió la finalización de algunas catástrofes con la salida en procesión de determinadas imágenes de santos patronos, este hecho fue interpretado como verdaderos milagros. Asimismo, el constante trabajo evangelizador de los misioneros contribuyó a que los nativos aceptasen, al menos exteriormente, la eficacia de las ceremonias y ritos cristianos efectuados ante las catástrofes naturales y, en particular, las volcánicas.

Según los casos estudiados, el siglo XVII en América se constituyó en un período de adaptaciones y de mimetismos religiosos en el que los indígenas y los españoles compartieron inevitablemente las vivencias catastróficas, por lo que entre ambos grupos étnicos se fue creando una respuesta armónica ante las crisis. Además, es evidente que los dos colectivos se necesitaban para superar in situ los efectos negativos provocados por los distintos procesos naturales que les perjudicaban; hasta tal punto era así que se ha podido observar que unos y otros se apoyaban en las labores de reconstrucción y de abastecimiento al ser la única respuesta eficaz que podían desarrollar los propios ciudadanos ante estas situaciones, sobre todo teniendo en cuenta los limitados recursos económicos de que disponían. Es evidente que esta colaboración fue más eficaz durante el transcurso del siglo XVII y cuando la evangelización se fue generalizando en los territorios colonizados e incorporados a la Monarquía hispánica. 
Como se ha expresado durante el desarrollo de esta investigación uno de los rituales que articularon la respuesta de los hispanos ante los desastres fueron las procesiones con características especiales dependiendo de la gravedad de la situación y la extensión del proceso natural en el tiempo. De este modo, y a semejanza con los ceremoniales de la Semana Santa en la Península, los primeros en asumir la organización de estas respuestas colectivas, como el obispo Marroquín tras la ruina de Santiago de los Caballeros de Guatemala en 1541, activaron un modelo que fue perfeccionándose durante la segunda mitad del siglo XVI y especialmente durante el siglo XVII, debido a la alta frecuencia de sucesos catastróficos que se produjeron en la América española como consecuencia de la activa geodinámica regional.

\section{Fuentes y bibliografía}

Álvarez SANTAló, León Carlos y otros, La religiosidad popular, tomo II, Barcelona, Anthropos, 1989.

AMUNÁTEGUi, Miguel Luis, El terremoto del 13 de mayo de 1647, Santiago de Chile, Imprenta Cervantes, 1882.

Barros Arana, Diego, Elementos de Jeografía Física, Santiago de Chile, Imprenta de la República, 1871.

Benavente, Toribio de, Memoriales o Libro de las Cosas de la Nueva España y de los Naturales de ella,

MÉXICO, Universidad Autónoma de México, 1971.

CAlancha, Antonio de la y TORREs, Bernardo de, Crónicas Agustinianas del Perú, 2 t., Madrid, CSIC, 1972. CORTÉS PEÑA, Antonio, «Entre la religiosidad popular y la institucional. Las rogativas en la España Moderna», Hispania, LV/191 (1995): 1027-1042.

EGIDO, Teófanes, «La religiosidad y los españoles (siglo XVIII)», Actas del Coloquio Internacional Carlos III y su siglo, tomo I, Madrid, Universidad Complutense (1990): 767-792.

ESQUiVel y NAVIA, Diego de, Noticias cronológicas de la gran ciudad del Cuzco, tomo II, Lima, Fundación Augusto N. Wiese, 1986.

Estupiñán, Tamara, Volcán Pichincha. Erupciones, destrucciones e invenciones, Quito, Banco Central de Ecuador, 1998.

FUENTES Y GUZMÁN, Francisco, «Recordación Florida», en Obras Históricas, tomo 1, Madrid, Ediciones Atlas, 1969. 
Gage, Tomás, Nueva relación que contiene los viajes de Tomas Gage en la Nueva España, París, Librería de Rosa, 1838.

JiMÉnEZ DE LA EsPadA, Marcos, Relaciones Geográficas de Indias, Perú, tomo 1, Madrid, Ministerio de Fomento, 1881. Disponible en: http://bibliotecadigital. aecid.es/bibliodig/es/consulta/registro.cmd?id=1109

JIMÉNEZ DE LA ESPADA, Marcos, «Una ascensión a el Pichincha en 1582», Boletín de la Sociedad Geográfica de Madrid, XXIV/1 (1888): 90-104. Disponible en: http://prensahistorica.mcu.es/es/publicaciones/numeros_por_mes.cmd?idPublicacion $=1001149 \&$ an $0=1888$

Juan, Jorge y UlloA, Antonio de, Relación Histórica del Viaje a la América Meridional hecho de Orden de S. Mag. Para medir algunos grados de meridiano terrestre, y venir por ellos en conocimiento de la verdadera figura, y magnitud de la Tierra, con otras varias Observaciones Astronómicas, y Phisicas (1748), Madrid, Fundación Universitaria Española, 1978, 2 tomos (edición facsimilar).

Lizana, Elías, Colección de documentos Históricos del Archivo del Arzobispado de Santiago, tomo II, Santiago de Chile, Imprenta Chile, 1920.

LÓPEZ DE GÓmARA, Francisco, Historia General de las Indias (segunda parte), Conquista de Méjico, Barcelona, Editorial Iberia, 1966.

Medina, José Toribio, Colección de Historiadores de Chile y Documentos relativos a la Historia Nacional, tomo XXXV: Actas del Cabildo de Santiago (1618-1619), Santiago de Chile, Imprenta Elzeviriana, 1901.

Medina, José Toribio, Colección de Historiadores de Chile y Documentos relativos a la Historia Nacional, tomo XXXV: Actas del Cabildo de Santiago (1655-1656), Santiago de Chile, Imprenta Elzeviriana, 1908.

MurúA, Martín de, Historia General del Perú, Madrid, Historia 16, 1987.

ocaña, Diego de, A través de la América del Sur (inicios del siglo XVII), Madrid, Historia 16, 1987.

Ovalle, Alonso de, Histórica relación del Reino de Chile y de las missiones y ministerios que se exercita en él la Compañía de Jesús, Roma, Francisco Caballo, 1646.

Palacios, Alfredo, Entre ruinas y escombros. Los terremotos en Chile durante los siglos XVI al XIX, Valparaíso, Ediciones Universidad de Valparaíso, 2015.

Petit-Breuilh, M. ${ }^{a}$ Eugenia, «Conjuros y exorcismos ante los desastres naturales en Hispanoamérica (siglos XVI-XVIII)» en David González Cruz (ed.), Ritos y ceremonias en el mundo hispano durante la Edad Moderna, Huelva, Universidad de Huelva, 2002: 331-351. 
Petit-Breuilh, M. ${ }^{a}$ Eugenia, La historia eruptiva de los volcanes hispanoamericanos (siglos XVI al XX). El modelo chileno, Lanzarote, Ayuntamiento de Lanzarote, 2004a.

Petit-Breuilh, M. ${ }^{a}$ Eugenia, Desastres naturales y ocupación del territorio en Hispanoamérica, Huelva, Servicio de Publicaciones de la Universidad de Huelva, 2004b.

Petit-Breuilh, M. ${ }^{a}$ Eugenia, Naturaleza y desastres en Hispanoamérica. La visión de los indígenas, Madrid, Sílex ediciones, 2006.

Petit-Breuilh, M. ${ }^{a}$ Eugenia, «Diosas, vírgenes y chamanes femeninos en el mundo indígena hispanoamericano durante el Antiguo Régimen» en David González Cruz (ed.) Vírgenes, reinas y santas. Modelos de mujer en el Mundo Hispano, Huelva, Servicio de Publicaciones de la Universidad de Huelva, 2007: 215-233.

Petit-Breuilh, M. ${ }^{a}$ Eugenia, «Miedo y respuesta social en Arequipa: la erupción de 1600 del volcán Huaynaputina (Perú)», Obradoiro de Historia Moderna, 25 (2016): 1-28. http://www.usc.es/revistas/index.php/ohm/article/view/3154 PONCE, Pilar (edit.), Relaciones Geográficas de la Audiencia de Quito, siglos xvi al xix, 2 tomos, Madrid, CSIC, 1991.

REMESAL, Antonio de, Historia General de las Indias Occidentales y particularmente de la Gobernación de Chiapa y Guatemala (1619), Madrid, Ediciones Atlas, 1964.

RODRÍGUEZ, Juan, Relación del espantable terremoto que agora nuevamente ha acontecido/ en las Indias en una ciudad llamada Guatimalal es cosa de grande admiración/ y de grande exemplo para que Todos nos enmendemos de nuestros peccados/ y estemos apercibidos para quando dios fuere servido de nos llamar. Toledo [s.n.], 1543.

Serrano Martín, E., Muerte, religiosidad y cultura popular. Siglos XIII-XVIII, Zaragoza, Institución «Fernando el Católico», 1994.

VÁsQUeZ DE ESPINOSA, Antonio, Compendio y descripción de las Indias Occidentales (segunda década del siglo XVI). Manuscrito. Biblioteca Apostólica Vaticana, Barb. lat. 3584.

VÁSQUEZ DE ESPINOSA, Antonio, Compendio y descripción de las Indias Occidentales (segunda parte), tomo 68b, Madrid, Historia 16, 1992.

Verdadera relación del Gran Temblor y terremoto que Dios N. Señor fue servido de embiar a la Ciudad del Cuzco, a 31 del mes de Marzo (...) de 1650, México, Viuda de Bernardo Calderón, 1650. 
Religiosidad y rituales hispanos en América ante los desastres (siglos XVI-XVII):

VetanCuRT, Agustín de, Teatro Mexicano. Descripción breve de los sucesos ejemplares, históricos, políticos, militares y religiosos del Nuevo Mundo Occidental de las Indias, México, Doña María de Benavides viuda de Juan de Ribera, 1698. Vicuña Mackenna, Benjamín, Ensayo histórico sobre el clima de Chile (desde los tiempos prehistóricos hasta el gran temporal de julio de 1877), Valparaíso, Imprenta del Mercurio, 1877. 